\title{
Aportación al estudio de la alfarería femenina en la Península Ibérica: La cerámica histórica de Alcorcón (Madrid)
}

\author{
Madre mía, quién me diera \\ una rapaza de Faro, \\ el trepadoriu y la rueda \\ y el tarreñón con el caldo ${ }^{1}$.
}

Cualquier pieza cerámica se compone de una mezcla de tierra y agua que posteriormente transforma su consistencia mediante un fuego controlado por las corrientes de aire. Los cuatro elementos de la naturaleza se aúnan en las vasijas de barro, pero no sirve cualquier tierra, el agua debe estar siempre en su justa proporción y tanto el fuego como el aire juegan un papel decisivo para el éxito o fracaso de todo el proceso. El dominio de la alfarería popular, transmitido de forma exclusiva dentro de la tradición familiar (de padres a hijos) tiene mucho de proceso mágico, reservado a sectores sociales iniciados y ha dado lugar a no pocas creencias, ritos, tabúes y mitos; la mayoría de los cuales afectan más a las mujeres, alfareras o no, que a los hombres, ligándose a lugares en los que se emplea una tecnología arcaica y, por tanto, escasamente documentados en Europa donde la herrería ha acaparado los valores mágicos y místicos que hubieran podido conferirse a esta actividad $^{2}$.

1 Copla popular asturiana, tomada de José PÉREZ VIDAL, La cerámica popular española, zona norte con noticias relativas a la influencia portuguesa en la cerámica gallega (Barcelos: Cuadernos de olaria 1, 1983), p. 66. (En nota a pie de página, el autor aclara que el trepadoriu es un trozo de badana mojada con el que los alfareros pulen y alisan la superficie de las piezas. También menciona que «el tarreñón con el caldo" puede referirse tanto al recipiente con agua arcillosa en que se remojan las manos durante el modelado, como, más presumiblemente, a la garantía de obtener alimentos gracias a los ingresos obtenidos con la alfarería).

2 Claude LÉvi-Strauss, La alfarera celosa (Barcelona: Ediciones Paidós, 1986), pp. 18 y ss. Probablemente la Península Ibérica sea en alguna medida la excepción que confirma la regla. No he podido consultar la obra de Alfredo GARCía ALÉn, Alfareria na literatura popular galega (Vigo: Ed. Galaxia, 1980) que seguramente enriquece el panorama sobre el tema. 
Entre los pueblos primitivos, históricos o contemporáneos, la norma es que la mujer sea la encargada de la fabricación cerámica ${ }^{3}$ valiéndose de sistemas de modelado y cocción muy elementales como la aplicación de rollos en espiral (urdido), para la formación de las piezas, y la cocción al aire libre o en hornos de una sola cámara. Mientras, son varones los alfareros de las piezas torneadas y también, con frecuencia, son ellos los horneros en construcciones de dos cámaras, incluso en lugares donde la alfarería es femenina. Además, frente al carácter de actividad marginal y economía subsidiaria que normalmente caracteriza a la actividad en manos de mujeres, los hombres están mucho más profesionalizados haciendo del oficio su principal fuente de recursos, cuando no la única. A nuestro juicio no se trata del siempre aducido "mayor conservadurismo femenino"; al menos en este caso, las diferencias en la constitución física según el sexo, condicionan el empleo de uno u otro sistema de trabajo (modelado o urdido). Todas las fases del proceso de fabricación son duras y penosas; hay que arrancar la arcilla del terreno, llevarla al alfar, mezclarla con agua batiéndola, pisarla, amasarla,..., transportar una y otra vez las pesadas, frágiles y voluminosas piezas: del torno, al secadero, al almacén, al horno, a los mercados, ... Pero, para el torneado que aprovecha la fuerza centrifuga en ruedas de movimiento rápido; para abrir y levantar una detrás de otra las pellas de barro, además de pericia y conocimientos, se requiere un gran desarrollo muscular en los brazos, siendo una labor mucho más adecuada para el hombre.

En la Península Ibérica, aunque se documenta la producción cerámica desde el 6000 a. C., con un estilo propio consolidado en el V milenio (la cerámica cardial), la técnica de torneado no es practicada hasta finales de la Edad del Bronce, principios de la del Hierro, siglos viII-VII a. $\mathrm{C}^{4}$. Con toda probabilidad fue implantada por las colonizaciones fenicias y griegas, a las que tanto debe la cultura ibérica, con una producción cerámica simbólica y no utilitaria, de gran finura y belleza. También los hornos de dos cámaras aparecen ya en este periodo. Aunque no contamos con imá-

3 Ver C. LÉVI-STRAuss, op. cit. y Margot DiAs, «Técnicas primitivas de olaria (com refêrencia especial á África)", Actas do Congresso Internacional de Etnografia. Promovido pela Câmara Municipal de Santo Tirso de 10 a 18 de julbo de 1963 . Vol 4. ${ }^{\circ}$ Colóquio de etnografia comparada (Lisboa: Junta de investigações do Ultramar, 1963), pp. 245-274.

4 Luis Carlos JuAn TOvar, "Alfares y hornos de la Antigüedad en la Península Ibérica: algunas observaciones en torno a su estudio", Tecnología de la cocción cerámica desde la Antigüedad a nuestros dias. Ponencias del Seminario celebrado en el Museo de Alfarería en Agost (Alicante) del 4 al 6 de octubre de 1990 (Agost: Asociación de Ceramología, 1992), pp. 67-68. 
genes de alfareros de la época, ni restos del tipo de rueda, si nos fijamos en las procedentes de otras culturas del Mediterráneo oriental, veremos que los operarios son siempre varones, que por cierto no empleaban un torno alto, sino una gran rueda baja muy semejante a la que ha llegado hasta nuestros días en Faro y Zarzuela de Jadraque ${ }^{5}$. El torno alto o de pie, hoy totalmente extendido es, en realidad, una invención muy reciente. Las primeras imágenes con que contamos proceden de la Italia del siglo XVI, a donde se supone que llegó por influencia del occidente islámico a través de la cerámica persa. También se sabe que en Francia no se conoció hasta el xviI, en Alemania, el xviII, o Rusia, el xIX, aunque lo más probable es que ya en el XviII estuviera implantado en toda la cuenca del Mediterráneo ${ }^{6}$.

Pero en la Península Ibérica, estos avances han coexistido, llegando hasta nuestros días, con producciones mucho más arcaicas, caracterizadas por ser obra de manos femeninas, lo que ha generado no pocos estudios e investigaciones. Éstas, lamentablemente, se suelen centrar en los alfares de una determinada localidad, o a lo sumo provincia o región geográfica, siendo normal que en España se ignoren los datos portugueses ${ }^{7}$. Además las noticias anteriores al siglo XIX, sólo en las publicaciones más recientes ocupan el destacado lugar que merecen. Asimismo, rara vez, se ha intentado dar una explicación global sobre la distribución geográfica de los centros primitivos o las causas de su tenaz supervivencia durante siglos, junto a otros mucho más modernos. La tendencia a disociar y tratar de forma independiente la evolución de tornos, hornos, tipos de piezas y aspectos socio-económicos del oficio tampoco ha contribuido a la obtención de una visión global. El presente trabajo centrado en las noticias históricas sobre la cerámica de Alcorcón, no pretende subsanar todos estos aspectos, pero, al menos, y al hilo de las datos proporcionados por unas u otras fuentes, nos permitirá una reflexión generalizada.

5 José PÉREZ VIDAL, "Dos ruedas asturianas de alfarero", Revista de etnografía, 22 (1968), pp. 1-21; Eulalia CASTELLOTE, La alfarería popular en la provincia de Guadalajara (Guadalajara: Institución Cultural "Marqués de Santillana", 1979), pp. 182-185.

6 Jorge DIAS, " $\mathrm{Da}$ olaria primitiva ao torno de oleiro com especial referência ao norte de Portugaln, Revista de etnografia, IV, I (1965), pp. 16-17.

7 Referencia obligada es el trabajo de Wulf KöPKE, "Frauentöpferei in Spanien", Baessler Archiv. N. F. XXII, (1974), pp. 335-441, lamentablemente de difícil consulta en España. Más accesible y de gran acierto en su enfoque y reflexiones resulta el trabajo de Emili Sempere FerRándiz, "Catalogación de los hornos de España y Portugal, Tecnología de la cocción cerámica desde la Antigüedad a nuestros días. Ponencias del Seminario celebrado en el Museo de Alfarería en Agost (Alicante) del 4 al 6 de octubre de 1990 (Agost: Asociación de Ceramología, 1992), pp.185-229. 
En 1966 Natacha Seseña ${ }^{8}$ publicó un artículo donde algunas referencias históricas y literarias ${ }^{9}$ sobre los pucheros de Alcorcón completaban la información obtenida en el trabajo de campo realizado en el último alfar de la localidad. Poco se podría añadir a la documentación directamente obtenida en aquel centro ${ }^{10}$, hoy extinguido, y que además estaba ubicado en un pueblo limítrofe con Madrid, actualmente absorbido por el crecimiento metropolitano, alterándose, hasta su total desfiguración, su primitiva personalidad. Sin embargo, mientras consultábamos algunas fuentes madrileñas, nos hemos encontrado con que, al menos hasta el siglo XIX, las mujeres eran las encargadas del modelado, además de interesantes y numerosos datos sobre el oficio que a nuestro juicio justifican sobradamente la vuelta al tema.

La llamada alfarería femenina en la Península Ibérica está ligada a un tipo de rueda baja: rueda de mano, torno de crucetas o "roda de mulheres", que funciona más como mesa giratoria de movimiento lento que como verdadero torno, provocando que la confección de las piezas se realice preferentemente por el sistema de urdido, o aplicación de rollos en espiral. Su presencia está bien documentada en un área geográfica situada al NO (ver fig. 1) en zonas montañosas interiores de difícil acceso y mal comunicadas, comprendiendo localidades portuguesas situadas entre el Miño y el Duero, como Pinela (1) —el número entre paréntesis corresponde a su localización en el mapa- y Malhada Sorda (2) ${ }^{11}$ o las zamoranas de Moveros (3) y Pereruela (4) ${ }^{12}$. Pero estos centros forzosamente deben re-

8 Natacha SESEÑA, "Pucheros de Alcorcón", RDTP, XXII (1966), pp.125-134.

9 Recogía la autora referencias de literatos del xviI, tales como Agustín Moreto y Diego de Torres Villarroel, tomadas de José FRADEJAS Y LEBRERO, Geografía literaria de la provincia de Madrid (Madrid: CSIC/AIEM, 1958), además de las noticias decimonónicas proporcionadas por Antonio PONZ en su Viaje por España y las del Diccionario de Pascual MADOZ.

10 Tal vez lo único sea la supervivencia de esta tradición en La Adrada (Ávila) gracias a la instalación de un alfarero alcorconero, Andrés Ortega. Véase Pablo ToRRES, Carlos LAORDEN y José María GarCía MERINO, Alfarería de Ávila (Ávila: Obra Cultural de la Caja General de Ahorros y Monte de Piedad de Ávila y Hogar de Ávila en Madrid, 1983), p. 29. En los últimos tiempos, se ha reimplantado la alfarería en Alcorcón, aunque dudamos que conserve algo de su primitivo carácter.

11 Joaquim SEllÉs, "Malhada Sorda, centro oleiro Beirão", Homenaje a don Luis de Hoyos Sáinz (Madrid, 1949), I, pp. 295-300; Margarinda RIBEIRO, "Contribuição para o estudo da cerâmica popular portuguesa", Revista de Guimarães, 3-4, vol. LXXII (1962), pp. 392-416; Jorge Dias, op. cit., pp. 5-31; Ernesto VeIGA DE Oliveira, Olaria en Malhada Sorda (Barcelos: Câmara municipal de Barcelos, Museo de olaria, Círculo catolico de o Parário, 1984).

12 Luis L. CORTÉs VÁzqueZ, "La alfarería de Pereruela (Zamora)", Zephyrus, V (Salamanca: 1954), pp. 141-163; Luis L. CORTÉS VÁZQUEZ, "Alfarería femenina en Moveros, Zamora", Zephyrvs, IX (1958). 


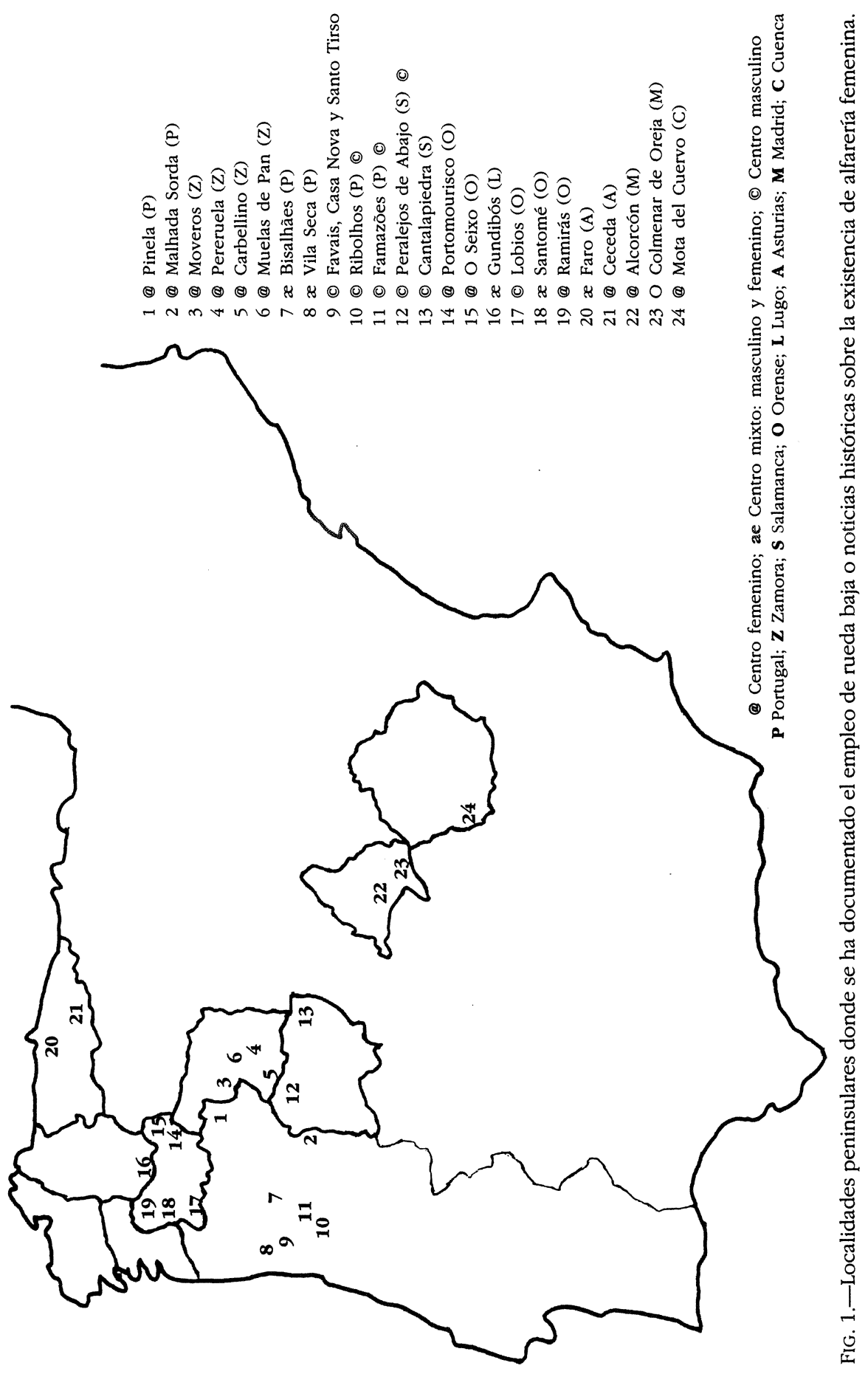


lacionarse y asociarse con otros muy cercanos; algunos ya extinguidos como los zamoranos de Carbellino (5) y Muelas de Pan (6) ${ }^{13}$, otros donde hombres y mujeres emplean este tipo de rueda, Bisalhães (7), además de aquellos donde ésta sólo es utilizada por varones, como los lusitanos: Vila Seca (8), Favais (9), Casa Nova (9), Santo Tirso (9), Ribolhos (10) y Famazões (11), o los salmantinos de Peralejos de Abajo (12) y Cantalapiedra (13) ${ }^{14}$.

También hay que añadir algunos lugares gallegos situados entre las riberas del Miño y el Sil ${ }^{15}$ abarcando la provincia de Orense y la zona meridional de Lugo - Portomourisco (14), O Seixo (15), Gundibós (16), Lobios (17), Santomé (18) y Ramirás (19)—. Estos últimos que debieron implantarse entre los siglos XVIII y XIX, ya que no son mencionados en fuentes históricas anteriores, en general, se extinguieron a principios del $\mathrm{xx}$ y están claramente emparentados con los portugueses, tanto por su vocabulario, como por la tipología de las piezas fabricadas, la variedades específicas en el tipo de rueda baja, o la posibilidad de ser accionados por hombres o mujeres de forma indistinta. Casi con toda certeza se deben a migraciones de lusitanos que buscaban hacerse con comarcas menos saturadas para la distribución de su obra ${ }^{16}$. El fenómeno tiene más importancia de lo que pueda parecer, la emigración de familias aisladas o grupos más amplios, procedentes de localidades donde hay una gran concentración (lo que con gran acierto Luciano García Alén bautizó como "las aldeas de alfareros", aunque en lugares meridionales habría que hablar de "pueblos"), en busca de mercados más favorables donde la competencia sea menor, o proporcionen alguna ventaja en el abastecimiento de las materias primas es un fenómeno frecuentísimo en toda la península y ha dado lugar a la documentación de instrumentos, técnicas y producciones, característicos de una determinada localidad, en otros puntos ajenos a ella. Probablemente la existencia de alfareras en Pereruela, tan

13 Herminio RAMOS PÉREZ, Cerámica popular de Zamora. Desaparecida (Zamora: 1980); Natacha SESENA, Barros y lozas de España (Madrid: Editorial Nacional, 1976), pp. 37-38.

14 Luis L. CORTÉs VÁZQUEZ, La alfarería popular salmantina (Salamanca: Centro de Estudios Salmantinos, 1953); Natacha SESEÑA, 1976, op. cit., p. 37.

15 Luciano García AlÉn con la colaboración de Alfredo García AlÉn y Xosé GÓMEZ VILASÓ, La alfarería de Galicia. I. Un estudio a través del testimonio cultural de las vasijas y de los alfareros-campesinos (La Coruña: Fundación Pedro Barrié de la Maza, 1984).

16 Luciano GARCÍA AlÉN, O paso de oleiros portugueses a Galicia: a sua viaxe polo derradeiro seculo (Barcelos: Câmara Municipal de Barcelos, Museu de olaria, Museu abierto 2, 1990). 
sólo a trece kilómetros de Zamora que constituía su principal mercado, se deba a esta causa. En la actualidad el único alfarero que mantiene la tradición de Gundibós, ha emigrado a Asturias ejerciendo su oficio en la Escuela de Cerámica Tradicional de Miranda de Avilés ${ }^{17}$.

Más problemático es tratar de emparentar con la zona mencionada, las endebles noticias sobre Faro (20) que en realidad es un barrio de Oviedo a menos de seis kilómetros. Posiblemente se relaciona con la desaparecida alfarería femenina de Ceceda (21) (Nava), conocida por los Diarios de Jovellanos, gracias a los cuales se puede comprobar que el tipo de rueda empleado no era el de crucetas ${ }^{18}$, sino un modelo de torno bajo, en el que ésta pieza es sustituida por un disco inferior, unido al superior por medio de una serie de vástagos. Es probable que en el resto de las localidades asturianas, donde hay indicios de la existencia histórica de alfareras, se empleara esta rueda, similar a a la documentada en Ordizan, Departamento de Hautes-Pyrénées ${ }^{19}$ (ver fig. 2).

Por último, su documentación en Mota del Cuervo (24) ${ }^{20}$, totalmente alejado del área descrita y no reseñado en fuentes históricas hasta el siglo $\mathrm{XIX}^{21}$ plantea (o planteaba) un problema especial; no sólo por su total

17 José Manuel FerTo, Cerámica tradicional asturiana (Madrid: Editora Nacional, Instituto de la Juventud y Promoción Comunitaria, 1985), p. 33.

18 José PÉREZ VIDAL, 1983, op. cit., p. 58 deduce la presencia de alfareras en Faro de dos coplas populares, una de ellas reproducida al inicio de nuestro estudio. Más cauta se muestra Esperanza IBÁÑEz ALDECOA, Cerámica tradicional de Faro (Oviedo: Principado de Asturias, Consejería de Industria y Comercio, 1987), p. 31, quien aunque aporta los nombres de dos mujeres en el censo de artesanos del Marqués de Ensenada (siglo XVIII), sólo encuentra menciones genéricas en obras posteriores como el Madoz o el Miñano y elude sacar consecuencia alguna de las coplas populares. Por último José Manuel FeITO, op. cit., pp. 40-42, añade que en Vega de Poja, según un manuscrito de principios de siglo firmado por Juan Uría, un alfarero local trajo a una alfarera faruca para que le enseñara sus técnicas. Además nos proporciona los nombres de otras localidades asturianas donde trabajaron las mujeres al torno como Miranda, Siero, LLamas del Mouro y Villayo. Sobre los tipos de torno asturianos véase también José PÉREZ VIDAL, "Dos ruedas asturianas de alfarero", Revista de etnografía, 22 (Museu de Etnografía e História, Junta Distrital do Porto), pp. 1-21.

19 José PÉrez VIDAl, 1983, op. cit., p. 54 y José M. FeITO, op. cit., p. 10-11.

20 Natacha SESEÑA, "La alfarería de Mota del Cuervo", RDTP, LXXII, 3..$^{\circ}$ y $4 .^{\circ}$ (1967), pp. 339-346; M. ${ }^{a}$ Dolores AlBertos, Andrés CARRETERo y Matilde Fernández MONTES, Estudio Etnográfico de la alfarería conquense (Tarancón: Diputación Provincial de Cuenca, 1978).

${ }^{21}$ En las Relaciones topográficas de Felipe II, al tratar de Mota del Cuervo no se menciona ni la alfarería, ni ningún otro tipo de industria, véase Eusebio Julián ZARCOBACAS y Cuevas (Cuenca: 1927), pp. 135-140. Por su parte, Madoz indica tan sólo la. existencia de alfarería sin ningún comentario ni dato sobre la actividad, como suele ser la norma al referirse a esta industria en localidades rurales. 
distanciamiento del NO peninsular, sino también por estar la población situada en un importante eje viario, precisamente el que procedente de la Comunidad Valenciana (zona donde la producción cerámica ha estado siempre en la vanguardia tecnológica peninsular) daba acceso a los productos mediterráneos, entre ellos las vasijas de barro, a Madrid y al resto de Castilla-La Mancha. La presencia histórica de alfareras en Alcorcón debe considerarse como un eslabón fundamental que facilita el paso por migraciones, desde su área originaria, en una primera fase al centro de la Península y posteriormente, a esta localidad situada casi en el SE. Más abajo esbozaremos algunas hipótesis sobre el cómo y por qué estas mujeres con sus técnicas arcaicas han podido llegar hasta nuestros días en Castilla-La Mancha, pero antes vamos ya a detenernos en los datos sobre Alcorcón (22).

La primera fuente donde se menciona la existencia del oficio es la contestación al cuestionario realizado por iniciativa de Felipe II. En 1575, cuando contaba con 170 vecinos, Antón Moreno, alcalde y Pedro Godino fueron nombrados para contestar el cuestionario. De ellos se nos dice que se eligieron por ser: "personas que tienen más noticia y experiencia de las cosas de dicho lugar, así porque el dicho Antón Moreno es hombre antiguo de más de setenta años, y el dicho Pedro Godino por ser hombre leído en historia y cosas antiguas y hombre curioso" ${ }^{22}$. Pero leyendo los datos sobre la alfarería, nos atrevemos a asegurar que al menos uno de ellos estaba familiarmente vinculado a la actividad:

A los cuarenta y dos capítulos dijeron que la mayor parte de los vecinos del dicho lugar, de tres partes las dos son hombres pobres, y la otra tercia parte tienen medianas haciendas, que el más rico es de cuatro mil ducados de hacienda, y los demás de allí a abajo. La granjería que tienen y lo que se hace y se labra en el dicho lugar mejor que en otra parte es cántaros, ollas, jarros y puchericos, y esto se labra tan bien y es el barro tan a propósito para el ministerio que son, que se llevan a muchas partes lejos, y se tienen en mucho en todo el reino, hacen esto las mujeres, es granjería de mucho trabajo y poco provecho, porque la leña y la hornija que se trae para los hornos les cuesta muy caro, porque van siete leguas por ello, y después de lo dicho se vende a muy moderados precios, y lo que más daños les hace es que se les quiebra mucha parte de la dicha obra que hacen, de manera que por no holgar ni tener otra cosa en que entender lo labran, y no por la ganancia que se les sigue de labrarlo ${ }^{23}$.

22 Alfredo Alvar EzQuerra (coord.) M. ${ }^{a}$ Elena García Guerra y M. ${ }^{a}$ de los Ángeles Vicioso RODRíGueZ, Relaciones topográficas de Felipe II. Madrid. Vol. I transcripción de los manuscritos (Madrid: Comunidad de Madrid, Consejería de Cooperación/ Consejo Superior de Investigaciones Científicas, 1993), p. 62.

23 Ibidem, pp. 67-68. 
Después de la sempiterna mención a la pobreza de los vecinos, sólo destacan la fama que al parecer ya tenía en la época la cerámica de Alcorcón, compuesta según el relato, de vasijas para líquidos (cántaros y jarros) y otras para fuego (ollas y puchericos), las últimas presumiblemente vidriadas con sulfuro de plomo. Seguidamente mencionan la calidad del barro que, según todas las fuentes posteriores y el renombre alcanzado debía ser verdaderamente excepcional. La producción de Alcorcón, no sólo abastecía al corregimiento de Madrid, sino que se llevaba a vender a lugares lejanos. Tema que conocerían bastante bien los varones, pues seguramente serían ellos los encargados de esta labor. Como Luis Cortés Vázquez señaló al tratar de Pereruela —localidad que, por cierto guarda grandes similitudes con Alcorcón por situarse junto a una gran villa o ciudad y por la fabricación de piezas refractarias y vidriadas- la producción cerámica en Castilla suele ser una empresa familiar en la que colaboran todos los miembros; cuando el alfarero es varón, la mujer suele encargarse de las labores auxiliares como preparación del barro, decoración, transporte y venta, pero en el caso de que sean cacharreras, los papeles se invierten y son ellos quienes se ocupan del resto ${ }^{24}$.

Buenos conocedores del tema, los informantes pasan a detallar las causas que provocan que sea una "granjería de mucho trabajo y poco provecho": En primer lugar, la escasez y lejanía de la leña y hornija que debían adquirir fuera del término municipal. La cantidad de combustible que consumen los hornos es muy elevada, especialmente en las cocciones de larga duración, como se requeriría para las piezas vidriadas que deben alcanzar temperaturas mínimas de unos 800 grados. El texto menciona también que se empleaban dos tipos de combustible, leña y hornija refiriéndose la primera, a troncos gruesos y la segunda, a leña fina o monte bajo que normalmente se utiliza durante "la tiemplan. La escasez de esta materia prima que tantos problemas ha causado siempre a los alfareros ${ }^{25}$, especialmente en lugares donde se concentran y por tanto se realizan múltiples hornadas es reiterada en otras tres respuestas del cuestionario $(26,23$ y 18$)$ :

rta. 18. A los diez y ocho capítulos dijeron que el dicho lugar es muy falto de leña, porque todo su término y dezmería no tiene encinas ni robles ni montes

24 Esta división del trabajo no se da en las alfarerías femeninas más primitivas documentadas en las Islas Canarias y el Norte de África, donde las mujeres también extraen y preparan el barro, prácticamente se achicharran durante la cocción en hogueras al aire libre, para finalmente ir con sus vasos a los puntos tradicionales de venta. Ver Margot DiAs, op. cit.

25 En la actualidad su elevado precio y las dificultades o imposibilidad para su obtención han provocado, según explican con frecuencia los alfareros, la sustitución de los hornos tradicionales por los eléctricos. 
que tengan otra leña, provéese de la leña del Real de Manzanares, que hay seis leguas hasta el dicho Real, los árboles que tiene son árboles de guindos y almendros como está dicho, tiene también aprovechamientos de las viñas y de lo que podan de sus árboles $(\ldots)^{26}$.

Por último, los informantes nos dejan testimonio del carácter subsidiario y marginal de la actividad y la escasa rentabilidad que se obtenía, achacada en primer lugar, al escaso margen comercial y en segundo, a que "se les quiebra mucha parte de la obra que hacen". Estas roturas se producirían con toda seguridad durante la cocción, proceso vital en el que se pone en juego el trabajo de semanas y durante el cual, aún en la actualidad es normal la pérdida de un $20 \%$ de la hornada ${ }^{27}$. Las causas que pueden provocar estas roturas son: que las piezas hayan entrado algo húmedas, que estén mal amasadas conteniendo burbujas de aire en sus paredes o impurezas (lo que especialmente ocurre con las urdidas), que se sucedan cambios bruscos de temperatura por un calentamiento o enfriamiento inadecuados, o por la existencia de corrientes de aire no controladas. Además, también pueden ocurrir los temidos hundimientos, totales o parciales, debidos a corrimientos por el estallido de alguna vasija, o a la mala colocación de la carga, sin preveer suficientemente las dilataciones y contracciones que sufre durante la cocción, o, en los casos más dramáticos, cuando toda la cerámica de la hornada se desploma y cae sobre la caldera por la rotura de los arcos o el sistema que se haya empleado para crear dos espacios. Si la escucha sucesiva de estallidos va ensombreciendo el semblante del hornero y el resto de las personas que le ayudan en su labor, el ruido sordo que provocan los hundimientos ocasiona una verdadera conmoción, agravada por el hecho de tener que continuar con la labor, con la certeza de que una parte se ha perdido pero sin saber hasta dónde alcanzan las roturas.

Como se ha documentado en el resto de la alfarería femenina peninsular y nos confirmará una fuente posterior, los hornos empleados debían ser de uso comunal y propiedad masculina. Sus dueños, o bien compran en crudo la obra de otros vecinos, o bien se quedan con un determinado número de piezas (la poya), siendo competencia de la alfarera o sus familiares varones, el abastecimiento de leña e incluso ir acercándola a la boca de la caldera. Mientras, el maestro hornero, casi como un alquimista, sólo realiza, o dirige el enhornado (colocación de las vasijas) y se ocupa de la cocción propiamente dicha.

\footnotetext{
26 Alfredo AlVAR EzQueRra, op. cit., p. 65.

27 Emili SEMPERE FERRÁNDIZ, op. cit., pp. 192-196.
} 
Aunque nos hemos alargado demasiado en comentar esta primera fuente, con brevedad queremos añadir que también menciona que debían traer de Parla y Fuenlabrada las tejas empleadas en las viviendas pues no se fabricaban allí. Además hay que resaltar la respuesta relativa a la salubridad del pueblo y sus habitantes que, como veremos es un tema que en documentos posteriores cobra cierta notoriedad al relacionarse con la actividad alfarera: "17 [...] es tierra llana y sana, y ha habido siempre en él hombres muy viejos de más de cien años, y que han vivido muy sanos" ${ }^{28}$.

Las Relaciones Topográficas de Felipe II fueron una aportación pionera para el conocimiento de las localidades rurales castellanas, pero no será hasta el siglo XviII cuando se confeccione el primer diccionario geográfico-histórico-estadístico de una forma completa y sistemática. Nos referimos al conocido como Diccionario de Tomás López que, por iniciativa eclesiástica, se realizó ajustándose a las divisiones por archidiócesis del territorio español, siendo contestado por los párrocos de cada población. El correspondiente a la Archidiócesis de Toledo, donde se incluía el corregimiento de Madrid, fue dirigido por Lorenzana en el último cuarto de siglo, encontrándose publicados los pueblos de la actual Comunidad Madrileña en los Anales del Instituto de Estudios Madrileños. Al licenciado Matías Ramos Pérez, cura de Alcorcón corresponde la información, fechada el 19 de enero de 1786:

Vecindario y enfermedades: se censan unos 150 vecinos. Las mujeres suelen padecer dolores reumáticos "provenidos de que ellas son las que fabrican y perciben muchas humedades, las que suelen ser muy rebeldes [....] los hombres padecen algunos raros accidentes de pecho y aseguran provienen del alcohol que causa tan terribles efectos como el antimonion. Para noticias curiosas sobre el particular se puede recurrir al médico que fue del lugar d. Juan Matheu, que hoy se encuentra en el hospital, tiene escrito algo sobre todo esto.

Industria: Fábrica de loza o barro "que sirve para el fuego sin duda es de la mejor que hay y de más duración. Por lo general se vende todo el año en Madrid y en sus contornos y en Alcalá, Guadalajara, Toledo, Mancha y Segovia y sus sierras. De ella se surten en la Real Cocina, la Real Botica y reales Hospitales y fábricas y Casas de Moneda. Ni se puede decir en cuanto ascenderá, bien que sus vecinos si fueran arreglados lo pasarían muy bien, por demasiado consumo".

Historia: No se sabe porqué se llama así el pueblo; tal vez proviene del "Alcor que se gasta para el vidriado" ${ }^{29}$.

28 Op. cit., pp. 67-68 (rta. 35) y p. 65 (rta.17) respectivamente.

29 Fernándo JiMÉNEZ DE GREGORIO, "Notas geográfico-históricas de los pueblos de la actual provincia de Madrid en el siglo XVIII, Anales del Instituto de Estudios Madrileños, II (1967), pp. 285. 
Al contrario que en el caso anterior, el informante ni debía ser natural de la localidad, ni estar vinculado a la alfarería, pues, aunque es la única industria mencionada, la información es mucho más parca, limitándose a confirmar la fama y calidad del barro refractario y los puntos de venta. Por los últimos podemos ver que en la época, Alcorcón abastecía a los principales centros oficiales y Reales Fábricas. Además, la distribución llegaba a la mayoría de las áreas limítrofes, entre ellas La Mancha, donde un siglo después encontraremos las primeras noticias sobre la existencia de alfarería en Mota del Cuervo.

Sin embargo, la elevada producción no parece que conllevara un aumento de la riqueza de los habitantes; en el siglo XVI los encuestados sabían el porqué, (el escaso margen comercial y la pérdida, por roturas, de buena parte de las piezas), pero, en este cuestionario, el cura les responsabiliza de no sacar partido a su actividad: "si fueran arreglados lo pasarían muy bien, por demasiado consumo". Que no nos encontramos ante un oficio especialmente rentable queda patente por el hecho de que en los dos siglos transcurridos, la población no sólo no ha aumentado sino que ha decrecido en veinte vecinos. Sólo al tratar de las enfermedades más características nos enteramos que eran mujeres las alfareras. La omisión del sexo de los trabajadores será una norma a partir de ahora. Así, Madoz no lo menciona en Alcorcón, Mota del Cuervo, Pereruela, Moveros o Carbellino, lo que sin duda, ha provocado, por estar en el siglo xx la producción alcorconera en manos masculinas, que haya pasado desapercibida su larga tradición femenina.

Por último, el carácter erudito del informante, licenciado y cura, le impulsa a aventurar una "etimología popular" para Alcorcón, según la cual debiera deducirse que en el origen del pueblo, la alfarería vidriada tuvo un peso decisivo. De alguna forma nos confirma que se trataba de la actividad más relevante y sobresaliente, aunque etimológicamente su deducción hoy nos resulte pintoresca ${ }^{30}$.

30 Sobre la verdadera etimología del nombre, tampoco nos convence demasiado la apuntada por Emilio NIETO BALLESTER, Breve diccionario de topónimos españoles (Madrid: Alianza Editorial, 1997), p. 39 que la considera un aumentativo de alcorque "especie de sandalia con suela de corcho, de donde se podría haber pasado a corcho, alcornoque", u "hoyo que se hace al pie de las plantas para detener el agua en los riegos". Por otra parte, todas las obras sobre toponimia árabe ignoran esta voz y la posibilidad de que derive como mozarabismo del aumentativo de qulla (vasija de barro en árabe) que también ligaría el nombre del pueblo a la alfarería. Quizá, como apuntaba Pilar García Moutón, se trate de un mozarabismo derivado del artículo árabe al y el término latino quercus, encina; aunque si en el momento de su fundación, éstas formaban un paisaje característico, en el siglo xvI, como hemos citado, ya no existían en el término. Faro, la localidad asturiana, también cuenta con una aetimolo- 
Casi coetáneas, las Memorias Políticas y Económicas de Eugenio Larruga nos proporcionan mucha más información:

La fábrica grande que hay en la Provincia, es la de Alcorcón; es de vidriado tosco, y ordinario, que lleva el nombre del mismo lugar; es bien conocida en Castilla, especialmente en Madrid: en su tráfico, y comercio se ocupa casi todo su vecindario (1) [Alcorcón tiene como unos doscientos vecinos] á excepción de unos 20 vecinos. No es fácil saber las piezas que los fabricantes hacen al año: todo se reduce á tinajas, barreños, ollas, pucheros, cántaros, copas, y cazuelas: tiene la fábrica 15 hornos, y las mugeres son aplicadas á sus faenas.

La proporción que tiene este pueblo de materias terreas, es de las mayores para las obras de alfarería, porque se componen de greda marga y un poco de materia jabonacea, que se funde con fuego muy violento; pero necesitan sus laborantes quien les fomente con la instrucción.

De igual clase son las alfarerías que hay en Almonacid, y Fuentelaencina: En otros pueblos se fabrica texa, ladrillo y valdosas, como tambien en las cercanías de Madrid ${ }^{31}$.

El texto aporta algunas noticias nuevas como que las vasijas eran conocidas por su "denominación de origen", o que los propios vecinos realizaban las ventas siendo su ocupación mayoritaria. El número de éstos indicado en nota a pie de página (que nosotros hemos incluido a continuación, entre corchetes), supera nada menos que en cincuenta, al estimado en el Diccionario de Lorenzana tan sólo dos años antes. Es probable que Larruga recogiera una cifra anterior al momento de la publicación de la obra, pero por otras fechas incluidas se puede ver que, en general, los datos publicados eran actuales. Tampoco parece probable que el cura de la localidad desconociera cuántos eran sus feligreses (aunque los fines recaudatorios del diezmo eclesiástico que tenían estas descripciones geográficas pudieron inducirle a rebajar las cifras); ni que se hubiera omitido mencionar alguna epidemia o enfermedad que provocara semejante merma en la población. Cualquiera de las dos obras puede contener errores en la transcripción, o tal vez hubo migraciones de grupos de familias a otros lugares, como por ejemplo a Almonacid y Fuentelaencina, donde ahora se menciona la existencia de producciones semejantes inexistentes en el siglo xvI, según las Relaciones de Felipe II, o también quizá a Colmenar de Oreja, que en este siglo ya

gía popular" que hace derivar Faro de Alfar, cuando en realidad parece más lógico que el nombre proceda de algún faro situado para iluminar el acceso a Oviedo, ver J. M. FEITO, op. cit.

31 Eugenio LARRUGA, Memorias políticas y económicas sobre los frutos, comercio, fábricas y minas de España (Madrid, 1788), III, p. 185. 
cuenta con una fábrica de tinajas y piezas vidriadas ${ }^{32}$, incluso a Mota del Cuervo.

Tampoco las cifras de población coinciden con las de otra obra contemporánea, el Censo de Floridablanca contestado en 1787, que menciona 595 habitantes (entre ellos había 117 matrimonios y 62 viudos que contaban como medio vecino, es decir unos 148 vecinos), estimación cercana a la recogida por Lorenzana. Mucho más escueta, la publicación cita 23 fabricantes que según nota al pie: "Lo son de la fábrica de barro y vidrio, 3 de ellos son del Vidriado de Talavera" ${ }^{33}$. En cualquier caso las discrepancias numéricas deben alertarnos sobre la fiabilidad y parcialidad de las llamadas fuentes históricas.

Volviendo al comentario de los datos proporcionados por Larruga, se añaden, a las piezas mencionadas en el siglo XVI, las tinajas y los barreños, que por su tamaño se ajustan más al sistema de urdido que al torneado y son o han sido las principales producciones en los lugares donde se emplea el torno de crucetas propio de la alfarería femenina peninsular. Entre las vasijas para fuego merece destacar la alusión a las cazuelas, que en nuestros días se fabrican masivamente en Pereruela. Se trata de un tipo de piezas que, como las de grandes dimensiones, pero por causas contrarias, no se adaptan bien al torneado produciéndose, sin embargo, con facilidad por el sistema de urdido. Si con los recipientes mayores, la gran cantidad de barro empleado imposibilita la confección de todo el cuerpo de una vez y se requiere realizar por urdido la parte inferior y dejarla secar y endurecer un poco antes de añadir más barro, con los platos y cazuelas, una vez hecha la base prácticamente está terminada la pieza, sus paredes son tan bajas que no requieren del sistema convencional para levantar el barro ("la tiradan); incluso en alfares donde se emplea el torno de pie, platos y cazuelas son frecuentemente confeccionados con ayuda de moldes.

Otra novedad destacable en el Larruga es la mención de que tan sólo existían 15 hornos (en el censo de Floridablanca se habla de 23); si tene-

32 Véase en Notas de esta misma Revista (tomo LII, cuaderno $2 .^{\circ}$ ) el trabajo de Alejandro PERIS BARRIO, "La tradición artesana de Colmenar de Oreja (Madrid)" que gracias a pertenecer al Consejo de Redacción hemos podido consultar antes de ser publicado. Como allí se puede ver, aunque Colmenar ha llegado a nuestros días como un centro especializado en grandes tinajas que por sus dimensiones no requieren de torno alguno para su urdido, sino que el alfarero gira alrededor de la pieza, en el XviII también producía obra vidriada, lo que acentúa sus similitudes y posible parentesco con la cerámica de Alcorcón.

33 Fernando JIMÉNEZ DE GREGORIO, La población de la actual provincia de Madrid en el censo de Floridablanca (1786) (Madrid: Diputación Provincial de Madrid, 1980), p. 14. 
mos en cuenta que más arriba se ha mencionado que la mayoría de los vecinos se dedicaban al oficio, nos hace deducir su uso comunal. Por último, al tratar del barro, no se limita a ensalzar su calidad, sino que detalla su composición, greda, marga y un poco de materia jabonácea. La greda es empleada sola en las piezas de agua confeccionadas por el sistema de urdido, pero para las refractarias suelen mezclarse varios tipos de arcilla, tal y como nos explica el documento y podemos corroborar por la comparación con los datos de Malhada Sorda ${ }^{34}$ (barro rojo y negro), Cantalapiedra (Salamanca) (amarillo - greda- y otro negruzco) ${ }^{35}$, o Pereruela (Zamora), "tierra" (greda) y barro fuerte "bermejo" ${ }^{36}$.

El comentario final "necesitan sus laborantes quien les fomente con la instrucción" enlaza con las noticias contenidas en otro tomo de la obra, teóricamente dedicado a la loza producida en Madrid, aunque, en realidad, casi sólo se habla de la de Alcorcón:

Ninguna de estas fábricas han sido ni la primitiva, ni las más útiles de la Corte. Las que tienen estas circunstancias son, las de Don Ramon Carlos Rodriguez, que he visto y examinado en la calle real de Lavapies, núm 6, y en la de San Carlos núm. 30 [.....] Igualmente se executa todo menage de cocina con la resistencia que tiene la de Alcorcón, pero con mucha mayor delicadeza y hermosura [.....] Manifestóme que había hallado la tierra á la salida de la puerta de Segovia, á un lado del sitio en que estuvo la ermita del santo Angel. Y preguntándole yo, en qué consistía, que siendo la tierra que gastan los de Alcorcón igual a la suya, no hacen obra tan buena? quedé sorprendido de su respuesta; púes me aseguró que era porque no querían; y prosiguió con estas palabras: Pues habiendo ofrecido yo mismo enseñarles, con sola la condición de que si la obra salía bien, habían de proseguir siempre haciéndola según les enseñase; pero si no salía perfecta, les daría cincuenta doblones para resarcirse de qualquier perjuicio que pudiera sobrevenirles de la experiencia, no pude reducirlos con toda la eficacia que en ello puse á que me admitiesen un partido tan ventajoso. Esta es una prueba de la falta de disposición que todavía hay en nuestros fabricantes para abandonar sus antiguos usos, y valerse de las luces que se van descubriendo para la perfección de las artes prácticas. Don Carlos Rodriguez mostró en su oferta un zelo patriótico, digno de todo elogio; pero los Alcorconeros manifestaron que no tienen luz, ni aun siquiera para conocer su propio interés. Yo no pude menos de extrañar con expresiones de indignación la conducta de los mencionados fabricantes; pero el Señor Rodriguez añadió: nada me admira que procedan así; la causa de un modo de pensar tan desatinado es el fanatismo y ciega adhesión del pueblo a los usos de sus mayores, por mas absurdos que sean; en vano se cansará nadie en quererlos sacar del camino trillado. No hay educación ni ideas; se contentan con intentar aquello que vieron quando niños; mis fábricas no se han manejado asi ${ }^{37}$.

\footnotetext{
34 Ernesto VeIga dE OliveIra, op. cit.

35 Luis CORTÉs VÁzQUEZ, op. cit., 1953, p. 23.

36 Luis CORTÉs VÁZQUEZ, op. cit., 1954, p. 148.

37 Eugenio Larruga, op. cit., tomo V, pp. 32-33.
} 
¿Qué innovación se negaron a introducir los alcorconeros, impidiendo que su obra fuera tan buena como la del fabricante madrileño? Me inclino a creer que se trataba de la sustitución de las ruedas bajas o de mano, por las altas o de pie, con las que se podría tornear mucho mas rápida y eficazmente, lográndose vasijas de perfecta simetría y finas paredes, "mas delicadas y hermosas". Si recordamos lo dicho anteriormente, el torno de pie estaba difundido en el siglo XviII por toda la cuenca del Mediterráneo, pero, su empleo en lugares alejados de la costa como ambas Castillas, debía ser aún minoritario, pudiéndose mostrar como un adelanto o una invención revolucionaria que se enfrentaba a la tradición secular alfarera. El tipo de horno o el sistema de cocción no parece que pudieran ser el motivo, pues la calidad y resistencia al fuego de las piezas refractarias vuelve a ser reiterada. En esta ocasión, se dio la espalda al futuro y no se escuchó al fabricante innovador, Carlos Rodríguez, pero la suerte estaba echada. En Alcorcón ya se sabía que existían otros métodos más eficaces de fabricación, y, además, la competencia no sólo estaba instalada en la Corte, robándole parte de su principal mercado, sino que también como hemos visto, el censo de Floridablanca recogía la existencia de tres fabricantes de Talavera en el mismo pueblo. Probablemente fue a partir de estas fechas, último cuarto del siglo xviII, cuando comenzaron a modernizarse las técnicas, pasando a manos masculinas y condenando a las alfareras, por su falta de competitividad, al abandono del oficio o a la emigración.

Todavía entre los tomos que Larruga dedicó a Madrid podemos encontrar más datos de interés, especialmente en el primero, dedicado al comercio. Por él sabemos que en la época existía en la capital un gremio de mercaderes de vidrio y vidriado y su enfrentamiento endémico con los vendedores ambulantes. Al igual que Cortés Vázquez documentó que sucedía entre Pereruela y Zamora ${ }^{38}$, la gran demanda que provocaba la ciudad no repercutía directamente en los cacharreros procedentes del lugar de fabricación, sino que pasaba a manos de revendones, en este caso organizados en un gremio con sanción legal. El relato con sus pormenores y excepciones que afectarían directamente a los vecinos alcorconeros merece su reproducción:

El gremio de mercaderes de vidrio, vidriado, y barro de esta Corte, se gobierna por los repartidores y apoderados que él mismo nombra. No tiene reglamento alguno formal, pero sí ganadas á su favor algunas providencias, que se reducen á una executoria conseguida por sus individuos en la Junta de comercio, por la qual se les concedió, que sólo ellos pudiesen vender al por menor las piezas de

38 Op. cit., 1954, pp. 162-163. 
vidrio, vidriado y barro que necesitasen los vecinos de Madrid; y por ella quedaron prohibidas semejantes ventas á los tragineros y fabricantes.

Corroboró esta executoria el Real Decreto del año de 1703, que se publicó para que ninguno pudiese vender en Madrid géneros de qualesquiera clase, no estando incorporados en el gremio á que correspondiese.

No obstante esto, porque algunos tragineros vendian sus obras, suscitó nueva instancia el gremio, que se determinó en el año de 1721, mandando, que en el caso de que los repartidores del gremio no comprasen á los forasteros y fabricantes los géneros que traen á vender a esta Corte, en el día que estos les avisasen, pudiesen dichos forasteros venderlos en los sitios y parajes públicos de Madrid, á excepcion de tiempo de feria, en que todos habían de ser libres.

Siguióse este método hasta el año de 1733, en que el gremio renovó sus instancias ó pretensiones, y ganó nueva executoria en el siguiente de 1734, para que sin embargo de la providencia del año 21, la libertad concedida a los forasteros, se entendiese con esta limitacion, que no tomando el gremio los géneros, pudiesen ellos venderlos en los mesones por mayor, y no en otro sitio, ni paraje público; y que solo pudiese executarlo por menor el que estuviese avecinado con tienda pública, é incorporado en el gremio, á excepción del tiempo de feria, en que todos han de ser libres.

Con esta providencia quedó contento el gremio; hasta que el año de 1758 se empezó a tolerar en favor del público, que los fabricantes y tragineros vendiesen por las calles y puestos públicos las manufacturas de barro; bien que todavía se mantiene el gremio en la posesion de ser el único vendedor del vidrio y vidriado de Talabera. Es indubitable, que así como con la concurrencia de las obras de barro ha conseguido el público un gran beneficio, igualmente lo lograría, si se permitiese la misma libertad en la venta del vidrio y vaxillas.

No obstante por una costumbre loable, de que se está en posesion por mas de cien años, se permite vender libremente toda especie de vidrio y vidriado, en las inmediaciones de las Ermitas del Angel y S. Isidro, en sus respectivas festividades; y aunque el gremio reclamó contra esta libertad, no obstante ha permanecido una costumbre tan conveniente.

La venta de vidriado ordinario por menor, parece ser libre, pues hay puestos de él, en la Plazuela de S. Estevan, y otros parajes; y para ello se cree haber precedido recursos y providencias favorables á los tragineros, las quales lo son igualmente para las respectivas fábricas, y al público de Madrid. Porque es incontestable, que quando se reduce la venta de algún género á personas determinadas, es lo mismo que estancarlo: del qual monopolio se sigue que los géneros se mantienen á precios muy subidos, el consumo se disminuye considerablemente, y las fábricas no prosperan; porque toda la utilidad se refunde en un corto número de personas, que pueden vender por menor, y dan la ley así á los compradores, como á los tragineros y fabricantes, que no tienen otro recurso para dar salida á sus géneros, que el venderlos á los mercaderes al precio que estos quieren pagarlos ${ }^{39}$.

La cita nos parece lo suficientemente amplia y explícita como para requerir más comentarios. Así, con los datos proporcionados por Pascual Madoz finalizaremos nuestro recorrido histórico:

39 Eugenio LARRUGA, op. cit., tomo I, pp. 348-352. 
CLIMA frío y temperamento sano naturalmente, si bien sus moradores padecen afecciones de pecho que se hacen crónicas, y cólicos saturninos, llamados vulgarmente de Madrid, achacado todo ello a las emanaciones del alcohol al quemarlo para vidriado [...... IND.: una tahona para surtir de pan al pueblo, una fab. de jabón, un almacén de aceite y 8 fábricas de alfarería ordinaria, pero superior en sus clase por su duración, ya sin vidriar, ya vidriado, cuyos barros tomados en la jurisd. del pueblo, aventajan en calidad á todos los del país, por lo que surten a la Corte y otros muchos pueblos cercanos y distantes. POBL.: 105 vecinos, 392 almas ${ }^{40}$.

Aunque extremadamente parco en esta voz, la decadencia de Alcorcón y su alfarería resulta evidente. De nuevo nos encontramos con un descenso espectacular de la población, que en menos de un siglo, se ha reducido a la mitad, o en una cuarta parte, según nos fijemos en los datos de Lorenzana (150 vecinos), o de Larruga (200). Mejor se puede apreciar por las cifras de habitantes: 595 en el censo de Floridablanca, 392 en el Madoz. Consecuentemente el número de fábricas (y aquí también se debe entender hornos), baja de los 15 que había cuando contaba con 200 vecinos (180 dedicados a la alfarería), a las 8 que tiene ahora entre 105 familias. Por otra parte, tampoco es ya la única industria o artesanía mencionada y además, nada se dice sobre si la alfarería era una actividad femenina o masculina. Parece como si la indiscutible calidad de la cerámica alcorconera no hubiera sido suficiente para lograr la consecuente prosperidad. Escaso margen comercial agravado por el corporativismo de los comerciantes madrileños, tareas duras, fuertes gastos en combustible que hay que traer de lejos, atraso en el tipo de tecnología empleada, ..... todas estas causas podrían ayudar a comprender, aun contando con la fuerte demanda, la decadencia del oficio.

Junto a ellas tenemos que tratar ahora otro problema suplementario; nos referimos a lo que Madoz llamó "las afecciones de pecho que se hacen crónicas" (según Lorenzana "raros accidentes de pecho") "y los cólicos saturninos llamados vulgarmente de Madrid". El vidriado con sulfuro de plomo parece ser, según ambas fuentes, el responsable de estas enfermedades profesionales que afectaban sobre todo a los hombres encargados de la cocción y otras tareas auxiliares. En el amplísimo trabajo de campo realizado por Emili Sempere sobre técnicas de cocción cerámica en la Península Ibérica, éste no sólo no encontró ninguna mención a los cólicos saturninos o a los "accidentes de pecho" entre los alfareros-horneros, sino que, por el contrario documentó la costumbre de prescribir a los afectados por las epidemias de gripe del siglo pasado y principios del

40 Pascual MADOZ, Diccionario Geográfico-estadístico-bistórico de España y sus posesiones de ultramar (Madrid, 2. ${ }^{\mathrm{e}}$ ed., 1846), tomo 1, p. 467. 
presente, que se acercasen a los respiraderos de los hornos durante la cocción para realizar inhalaciones, al parecer con muy buenos resultados ${ }^{41}$. Tampoco a nosotros nos relataron ningún caso en los numerosos alfares encuestados durante los setenta-ochenta y, hasta donde sabemos, sólo Eulalia Castellote ${ }^{42}$ documentó un cólico saturnino en el pasado, referido por los alfareros de Camporreal. Casualmente, se trata de otro más de esos centros alfareros, próximos a Madrid y Alcorcón que parecen surgir de la nada en el siglo xviII. Con toda probabilidad, estas enfermedades son provocadas por el sulfuro de plomo empleado para los vidriados, pero a nuestro juicio, no se producían por inhalaciones durante la cocción, sino durante el molido de los terrones del mineral, momento en que el polvillo en estado puro se alojaría en los pulmones o en el estómago produciendo los envenenamientos y las afecciones de pecho. Desde hace casi un siglo los alfareros adquieren la materia ya molida lo que explicaría la actual ausencia del mal.

El tema se sobredimensiona en las fuentes, al asimilarse al llamado "cólico de Madrid" que constituyó uno de los tres principales padecimientos de la villa, provocando la atención de la clase médica y una cuantiosa literatura científica (ya vimos que Lorenzana recogió cómo el facultativo de Alcorcón había escrito algo sobre el tema). La afección se atribuía a causas diversas, siendo una de ellas la asimilación con el cólico saturnino ${ }^{43}$, defendida por un prestigioso doctor a finales del xVIII, debida a la costumbre de conservar los alimentos en vasijas de barro mal vidriadas. Afortunadamente, y corroborando la fama de las piezas alcorconeras, en el siglo XIX fue desechada esta idea por tesis de médicos franceses que llegaron con las tropas napoleónicas a la corte, quienes lo consideraban como una enfermedad endémica en Castilla relacionada con los cambios bruscos de temperatura en las noches de verano. Todavía en el XIX volvió a pensarse en una intoxicación de origen plúmbico, aunque entonces achacándola al agua de Madrid, rica en ácido carbónico, que en verano producía la descomposición de las tuberías de plomo (lo que no resulta demasiado convincente ya que una mínima parte de la población tenía agua corriente en sus domicilios y las conducciones de los viajes de aguas eran de cerámica sin vidriar). La decadencia de la enfermedad, a partir de la inauguración del Canal de Lozoya que sustituyó a las aguas

41 Op. cit., p. 194.

42 Eulalia CASTELLOTE y Alfonso GARCÉs, Cerámica popular: Camporreal (Madrid: Diputación Provincial, Servicios de Extensión Cultural y Divulgación, 1978), p. 21.

43 Philip HAUSER, Madrid bajo el punto de vista médico-social (Madrid: Editora Nacional, 1979), pp. 309-310. 
subterráneas en el abastecimiento de la población ${ }^{44}$, parece confirmar su relación con este elemento, salvando el honor y la reputación de nuestra alfarería vidriada.

Pero, y volviendo a nuestro tema, aunque ha quedado constancia de la existencia de enfermedades profesionales tanto para mujeres, como para hombres, éstas se tachan de crónicas o rebeldes, nunca de mortales; el pueblo siempre es definido como "sano", mientras vemos cómo su población decrece progresivamente. Debemos reiterar la idea ya apuntada: durante los siglos XVIII y XIX se produjeron migraciones de grupos de alfareras con su familias, salieron de un pueblo con una larga tradición, para probar fortuna en otros, previamente conocidos por ser puntos tradicionales de venta. A nuestro juicio es el origen de la alfarería en Mota del Cuervo y probablemente en algunas localidades más que han llegado hasta nuestros días como producciones varoniles con torno de pie, especialmente las que confeccionaban tinajas, tinillos, barreños, orzas y demás grandes piezas ${ }^{45}$.

En el artículo que Madoz realizó sobre Madrid, también se dan noticias sobre los mercados. Al parecer, en este siglo, los cacharreros procedentes de los lugares de fabricación podían vender directamente su obra, pagando una tasa o alquiler:

Ferias y mercados. El año 1839 se construyeron por los pobres de San Bernardino unas sencillas y graciosas hileras de cajones a manera de tiendas, que se colocaron primero en la Plaza Mayor, y luego, por parecer reducido su espacio, en la calle de Alcalá, que es donde continúan poniéndose cada año, por los mismos pobres. El alquiler de estos puestos queda a beneficio de aquel asilo de mendicidad. La calle Alcalá, pues, debe considerase como el centro de la animación y estraordinario movimiento que se advierte en Madrid por aquellos días: en su primera parte se colocan puestos de nueces y avellanas, de esquisitos melocoto-

44 José ÁlVAREZ-SIERRA, Historia de la medicina madrileña (Madrid: Ed. Universitaria Europea, 1968), p. 114.

45 Cuando consultábamos los tomos del Larruga correspondientes a Cuenca y La Mancha nos sorprendió la gran cantidad de lugares en los que se cita la alfarería, ninguno de ellos ha llegado hasta nuestros días, excepto Priego que es nombrado de forma independiente y ya se mencionaba en las Relaciones Topográficas de Felipe II. Todos, al parecer, estaban especializados en la fabricación de tinajas y grandes piezas de barro basto que se vendían por La Mancha llegando hasta Valencia. Los centros alfareros se suelen o solían especializar en un tipo de producción, y por tanto, su existencia no impedía que se adquirieran de fuera otros vasos necesarios. Por otra parte, tampoco hasta el siglo XviII contamos con datos sobre la tinajería de Colmenar de Oreja ni la alfarería de Camporreal. Véase el trabajo de Alejandro PERIS BARRIO, publicado en este tomo de la RDTP y el de Eulalia CASTELLOTE y Alfonso Garcés, op. $c i t$. en el que podemos leer que las cazuelas y pucheros eran piezas características del centro. 
nes de Aragón, acerolas, manzanas, azufaifas y otras frutas: interpolados con estos, se ven algunos tinglados con juguetes y quincalla; luego las mencionadas tiendas de San Bernardo, en que tienen cabida géneros catalanes, mantas de Palencia, algunos tejidos de hilo, velones y otros objetos de la misma clase y juguetes; y por último mucha loza fina y ordinaria ${ }^{46}$.

Además, el autor incluye un cuadro en el que se detallan los arbitrios pagados por diversos géneros de mercancías para poder ser comercializados en la Corte. La cerámica ocupa dos apartados, uno dedicado al «barro" y otro al "vidriado". En el primero junto al de Alcorcón figuran con cifras superiores, el de Villa del Campo y Villaseca, siendo menores las de Navalmoral, Ocaña y Zamora ${ }^{47}$. Pero en la obra vidriada, Alcorcón mantiene su primacía absoluta sobre las piezas de Alcalá, Aragón, Puente, Talavera y Toledo. Realmente siempre fue la calidad extraordinaria de la producción para fuego la que acaparaba las alabanzas y es muy posible que las vasijas para líquidos (agua, vino, leche o aceite) no resultaran tan buenas obteniendo una menor demanda ${ }^{48}$. Pero también podría suceder, como en Malhada Sorda y Cantalapiedra, que existiera una especialización de cada alfar según las técnicas empleadas y el tipo de piezas ${ }^{49}$, dedicándose cada productor o productora (alfareras y horneros) a unas u otras vasijas. Lo cierto es que si la industria en Mota del Cuervo procede de la de Alcorcón, aquí sólo se implantó cerámica sin vidriar, la de menor fama y venta en el Madrid decimonónico.

Las fuentes que hemos encontrado fueron redactadas y contestadas por hombres, lo que condiciona en gran parte el tipo de noticias que nos proporcionan; sabemos de tierras, de hornos, de combustible y venta, pero poco o nada sobre la actividad de las mujeres. Tan sólo que se trataba de una ocupación subsidiaria y marginal y que la humedad les producía

46 Op. cit., tomo 11, p. 1073.

47 Ibidem, p. 1058. No deja de ser significativo para explicar la presencia de alfarería femenina en Alcorcón, que Madrid fuera un punto de venta tradicional de la cerámica zamorana.

48 Así sucedía en Pereruela, a donde habitualmente se acercaban los cacharreros de Moveros (L. Cortés VÁzQuez, 1954, op. cit., p. 156) a vender cántaros, o en Mota del Cuervo, donde los lebrillos se fabricaban escasamente por preferirse los de Bailén (M. ${ }^{a}$ D. Albertos, A. Carretero y M. Fernández Montes, op. cit., p. 138).

49 En Malhada Sorda (población lusitana situada en la frontera con Salamanca) existía alfarería femenina y masculina, hoy sólo persiste la primera, cada sexo empleaba un tipo de torno y un sistema de modelado diferente: torneado o urdido. En Cantalapiedra, Salamanca, aunque siempre varones, utilizaban el torno de pie para la producción vidriada y la rueda de crucetas para las tinajas y otras grandes piezas. L. CORTÉs VÁZQUez, op. cit., 1953, p. 26 y ss. 

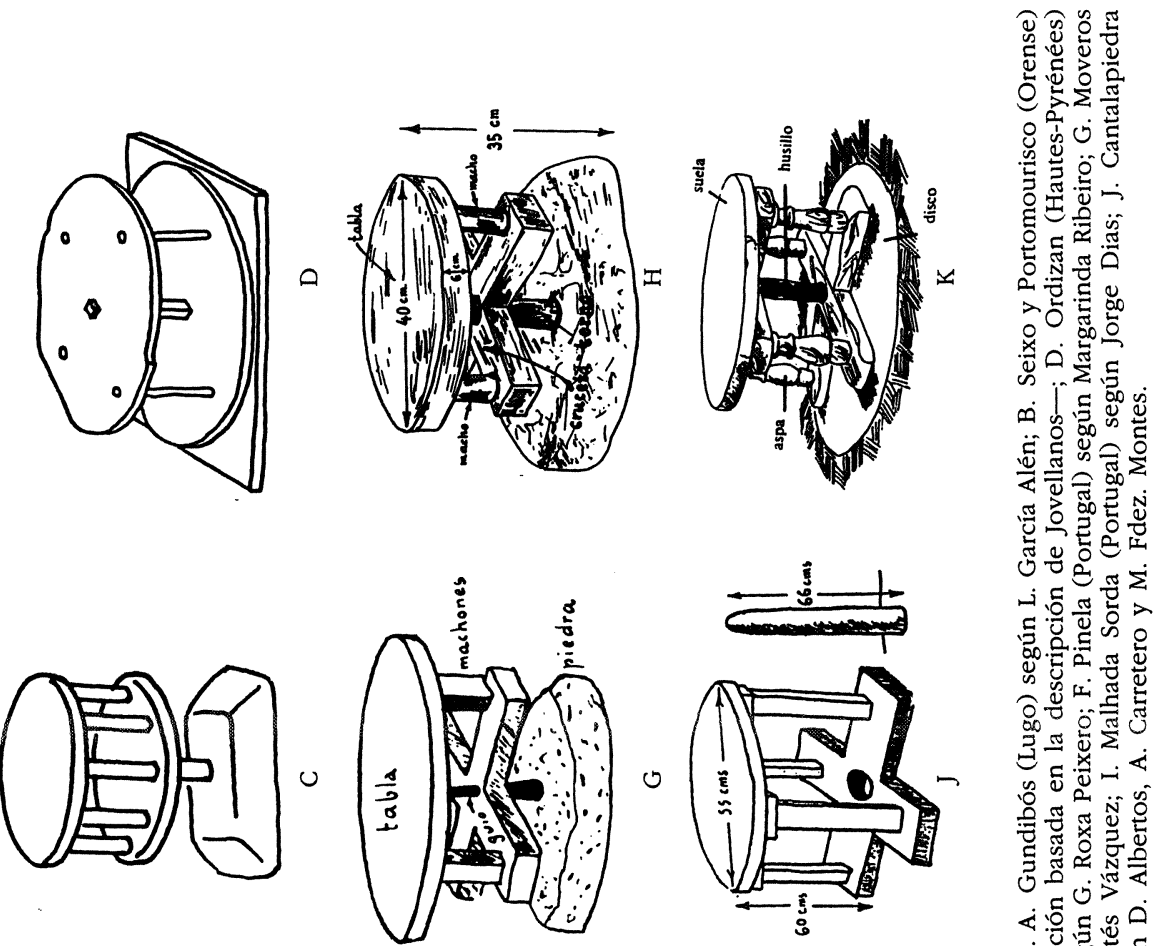

象兘澏
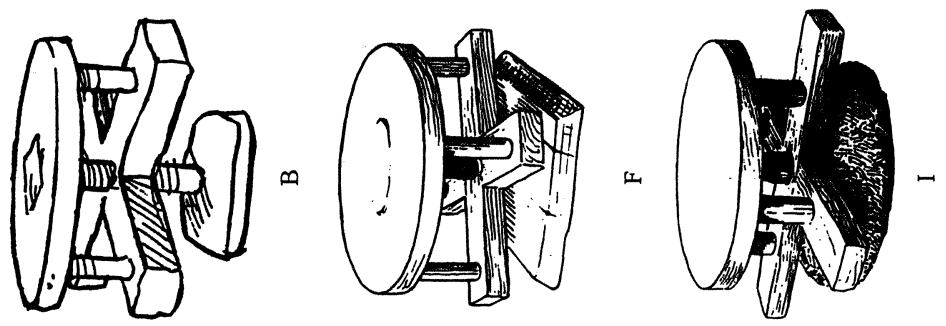

언론동

造

巳

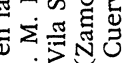

웜

要通

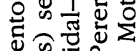

要江 要剀

워ㅇㅝㅛ

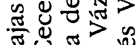

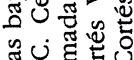

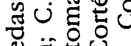

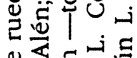

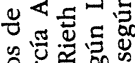

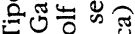

1.这可

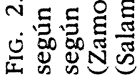


reuma. Para intentar ampliar nuestro conocimiento vamos a dar por verosímil nuestra hipótesis de que Mota del Cuervo es la heredera de la tradición alcorconera, y por la comparación de este centro con otros peninsulares, señalar los paralelos y similitudes más notables.

Primeramente nos ocuparemos de la tipología de ruedas bajas, de movimiento lento que para mayor claridad hemos colocado en la figura 2 según su orden geográfico de NO a SE. Desechadas las variedades de Ceceda (C) y Ordizan (D) por no ser de crucetas, entre las restantes también encontramos notables diferencias. Las de menor altura ocupan los lugares más occidentales y han llegado hasta nuestros días en manos de hombres, Vila Seca (E) o de empleo mixto, Gundibós (A) ${ }^{50}$. En ellas el alfarero trabaja sentado sobre una pequeña banqueta, siendo accionadas con la mano, de izquierda a derecha, ya que su escasa altura y la equidad entre la longitud del disco superior y los brazos de la cruceta inferior impiden cualquier otra fórmula (para las piezas más grandes en Gundibós los cacharreros se valían de otra persona para mover la rueda). Aunque algo más altas, también se impulsan con la mano los modelos muy similares y siempre en manos femeninas, de Pinela (F), Moveros (G), Pereruela (H) y Seixo-Portomourisco (B). Incluso, en las localidades zamoranas y en la lusitana, las mujeres trabajan de rodillas, más o menos sentadas sobre los talones según la altura de la pieza, lo que imposibilita el empleo de los pies. Es de destacar que en todos los casos hasta ahora tratados, al igual que ocurrirá en los restantes, se combinan técnicas de urdido, para la confección de las grandes vasos, y torneado durante el raído y pulido de las paredes o con piezas determinadas. Para la última operación, previamente se impulsa la rueda hasta que alcanza la velocidad necesaria y a continuación se trabaja con ambas manos ${ }^{51}$. Por último los modelos surorientales (Malhada Sorda, I, Cantalapiedra, J, y Mota del Cuervo, K) presentan interesantes variedades. En primer lugar su altura es notablemente mayor y también lo es la longitud de la cruceta que sobrepasa la del disco superior, muy marcadamente en el modelo de Malhada Sorda. Gracias a esto las alfareras pueden accionar la rueda, con la mano o con el pie izquierdo, según el tipo de pieza y la fase del modelado (se suele iniciar el giro con la extremidad superior, para continuar después con la inferior en grandes recipientes). Las mujeres trabajan sentadas sobre un taburete o de pie encorvándose sobre la cabeza del torno, con las vasijas de mayor tamaño. Sin embargo, con la rueda para tinajas de Cantalapiedra (J), todavía de mayor altura y de empleo masculino, el

so Margarinda RiBeiro, op. cit., p. 392 y L. GARCÍA AlÉN, op. cit., pp. 82 y ss.

51 Ibidem y Luis CORTÉS VÁZQUEZ, 1954 y 1958, op. cit. 
operario no impulsaba la rueda sino que se hacía ayudar por una segunda persona, normalmente un niño ${ }^{52}$ (no deja de ser indicativo de la mayor profesionalización que adquire el oficio en manos masculinas que, casi en la totalidad de los casos son varones quienes acuden al auxilio de otro durante el urdido, mientras que las mujeres se las arreglan solas). A pesar de las diferencias de altura y uso del ejemplar salmantino, su cercano parentesco con el de Mota del Cuervo es patente por el hecho de ser los dos únicos modelos con doble cruceta; ya que el disco superior no apoya directamente sobre los vástagos periféricos sino sobre otra aspa, lo que facilita el recambio de esta parte, sin duda la de mayor desgaste por el contínuo raído de las bases de las piezas para desprenderlas, una vez finalizado el modelado. También es sintomático que, mientras en los restantes el eje central se clava en piedras o en soportes de madera que permiten la movilidad del instrumento, tanto en Cantalapiedra como en Mota del Cuervo, éste se fijaba en un orificio practicado en el suelo que en la localidad conquense fue sustituido por un disco de arado en la década de los cincuenta ${ }^{53}$.

Además, el sistema de preparación del barro en Cantalapiedra (donde sólo estamos contemplando los datos referentes a la confección de tinajas) y en Mota del Cuervo es idéntico. En los dos sitios mezclan la cantidad justa de agua y greda, sin ningún tipo de depuración, eliminándose las impurezas, denominadas "gorullos" en ambos centros, "grolos" en Malhada Sorda), durante el amasado. También coinciden en la palabra "rollo" (en vez de" bolo" empleada en el resto de Salamanca, o "pella" en La Mancha) para denominar las porciones de barro preparadas para el modelado. Siguiendo con la nomenclatura igualmente podría añadirse que la denominación de "hornija", hallada en las Relaciones de Felipe II, para el combustible de la hornada, asimismo fue documentada en Cantalapiedra.

Sobre los posibles tipos de hornos históricamente empleados en Alcorcón, resulta más difícil establecer hipótesis por la ausencia o mala calidad de las descripciones y dibujos publicados. Como ya hemos dicho eran de uso comunal y propiedad de horneros especializados, tal vez simples agujeros cilíndricos excavados en el terreno, recubiertos, o no, de piedras o adobes. En ellos, la cocción se hace por contacto directo entre el fuego y las piezas (se trata de los tipos más primitivos en toda la Península Ibérica). A veces, en modelos muy similares, se documenta la formación rudimentaria de dos espacios, uno para el combustible y otro

52 Ver luis Cortés VÁzquez, 1953, op. cit.; Albertos, Carretero y Fernández MONTES, $o p$. cit. y E. VEIGA DE OlIVEIRA, $o p$. cit.

53 A. Albertos, C. Carretero y M. Fernández Montes, op. cit. 
para la carga, como parece requerir la obra vidriada. La separación se crea insertando falsos arcos, tubos de tiraje, muretes semirradiales o grandes tinajas en la parte inferior, sobre las que se apoyarán las vasijas que por arriba se cubren de cascote. Según Emili Sempere Ferrándiz, estos modelos están o estaban en uso en la mayoría de las localidades portuguesas donde se emplea el torno bajo, en Gundibós (Galicia) y en varios alfares asturianos masculinos o femeninos ${ }^{54}$. Además Luis Cortés Vázquez lo documentó, aunque ya en desuso en Pereruela (Zamora) ${ }^{55}$. En Malhada Sorda y Bisalhães (Portugal) la construcción, aunque de similares características no es ya subterránea sino que se delimita y protege con muros elevados sobre el terreno, como también en Seixo, Portomourisco, Moveros, en los hornos más recientes de Pereruela, Carbellino, etc. En estos modelos es o era normal que antes de finalizar el atizado de combustible, se cubrieran totalmente las piezas con tierra y césped, lo que provoca por la falta de oxígeno, la creación de una atmósfera reductora y el color negro de las piezas, con el cual, además, se disimulan los defectos de cocción.

Muy brevemente señalaremos las coincidencias morfológicas de algunas piezas que consideramos significativas, eliminando por tanto las de grandes recipientes como tinajas, tinillos y barreños que son siempre característicos de la cerámica urdida. Nos referimos, por ejemplo, a las existentes entre el cántaro de Moveros y la botija de vino de Mota del Cuervo $^{56}$, o la confección de jarros de ordeño, citada en el Larruga, y que aún hoy se documenta en Mota del Cuervo y en la madrileña cerámica de Camporreal.

Como reflejaba la copla asturiana con que iniciamos nuestro estudio, las alfareras eran requeridas en matrimonio antes que otras mujeres, pues aportaban a la economía familiar una fuente de ingresos suplementaria y así fue recogido por Margot Dias ${ }^{57}$ en el Norte de África y por Margarinda Ribeiro ${ }^{58}$ en Anceda (Portugal). En la misma línea se debe interpretar la mención hecha por Luis Cortés Vázquez de que en Pereruela, las jóvenes

\footnotetext{
54 Op. cit., pp. 202-204.

55 Op. cit., 1954, pp. 158-59. Véase también Wulf KÖPKE, Hornos alfareros. Sistemas de cocción en la alfarería tradicional española. Clases distribución y desarrollo [Marburger Studien zur vergleichenden Ethnosoziologie, 13] (Bonn: Dr. Rudolf Habelt Verlag, 1985). Sólo mencionamos los tipos de hornos empleados en centros que tienen alguna relación con nuestro estudio.

56 Luis CORTÉs VÁzQuez, op. cit., p. 101 y D. Albertos et al., op. cit., p. 145, respectivamente.

57 Op. cit., p. 269

58 Op. cit., p. 414.
} 
aprenden rápidamente el oficio, no comenzando "a ponerse a la rueda hasta los diez y siete o diez y ocho años, en general poco antes de casarse. Es raro que se pongan antes y si no es para casarse no suelen empezar hasta que los años o la fatiga obligan a sus madres a cederles el puesto" ${ }^{59}$.

El caso contrario, es decir el menosprecio de la cacharrera, a la que se reprochaba la constante suciedad en que vivía rodeada fue recogido por Luciano García Alén en Portomourisco ${ }^{60}$ y por Natacha Seseña y nosotros mismos en Mota del Cuervo durante las décadas de los sesenta y setenta ${ }^{61}$. Es significativo que en ambas localidades el oficio, no documentado hasta el siglo XIX, nunca fue una labor mayoritaria de la población femenina, pues sus laborantes se concentraban en un barrio, siendo mujeres ajenas las responsables de las críticas que especialmente eran vertidas y hacían mella en las jóvenes casaderas. ¿No se tratará de una forma de exclusión y rechazo social? No hay que olvidar la competencia desleal que suponía la existencia en el pueblo de un grupo exclusivo y cerrado, con la transmisión generacional, de madres a hijas, de un oficio capaz de generar una fuente de ingresos suplementaria para sus familias. Hoy esta artesanía ha desaparecido en Portomourisco, mientras que en Mota ya no hay un barrio, sino unas poquísimas y mimadísimas representantes, que, casi como una reliquia, mantienen unas técnicas y producciones primitivas y arcaizantes, de alta demanda y cotización como producto turístico. Muchas personas conocen el pueblo sólo por esta actividad y se acercan para visitar a sus representantes (algunas, como Dolores han alcanzado verdadera fama). Probablemente, todavía recuerdan el rechazo social y tal vez incluso padecen críticas e intentos de marginación, pero sus convecinas, aunque a regañadientes habrán tenido que admitir el prestigio de ser alfarera.

\section{MATILDE FERNÁNDEZ MONTES \\ Departamento de Antropología Instituto de Filología. CSIC}

59 Op. cit., 1954 , p. 146

60 Op. cit., p. 64.

61 Natacha SESEÑA, 1967, op. cit. y ALBERTOS et al., 1978, op. cit., p. 160, respectivamente. 
El artículo centrado en noticias de los siglos XVI al XIX sobre la cerámica de Alcorcón (Madrid), pone en evidencia el carácter femenino de la actividad en la época y sus principales aspectos junto con la problemática que acarreó su decadencia. Además, al hilo de los datos aportados se realiza una comparación y una reflexión generalizada sobre la alfarería femenina en la Península Ibérica, y las posibles migraciones que dieron lugar a su presencia en unos y otros puntos geográficos.

By focusing on 16th- through 19th-century records of pottery making in Alcorcón, province of Madrid, the author calls attention to the substantial involvement of women in this craft, among other aspects, as well as to the problems that its decline brought about. The author relies on this analysis to make a comparison with pottery making elsewhere, which leads her into a general discussion on women's pottery in Iberia and the possible migration flows that may account for the distribution of production centers. 